\title{
Hydrothermal Extraction of Microalgae Fatty Acid Influences Hydrochar Phytotoxicity
}

\author{
Christopher J. Ennis *, Joyce Clarke, Katherine Neate, Joana Cerejeira and Lewis Tull \\ School of Science and Engineering, University of Teesside, Middlesbrough, United Kingdom
}

Hydrothermal carbonization ( $\mathrm{HTC}$ ) of microalgae biomass for the production of triacylglycerides is a potentially valuable enabling technology for a waste water treatment-based integrated biorefinery. Here, HTC was used to treat Phaeodactylum tricornutum lipid-rich biomass producing a solid hydrochar from the surface of which adsorbed lipids were removed by hexane extraction following filtration of the solid hydrochar from the process liquid product. Approximately $7 \%$ of the input biomass was recovered and transesterified for qualitative and quantitative GC-MS analysis for fatty acid methyl esters. Transesterifiable lipids accounted for $94 \%$ of the material recovered by solvent extraction. Of the transesterified fatty acids (FA) analyzed, the majority was monounsaturated (40.4\%) and saturated (37\%) C-16 FA. Other FA detected included saturated and monounsaturated C-18 (7.7 and 1.9\%) and saturated C-14 (5.3\%) and

OPEN ACCESS

Edited by:

loannis V. Yentekakis,

Technical University of Crete, Greece

Reviewed by:

Costas N. Costa,

Cyprus University of Technology,

Cyprus

Adarsha Gupta

Deakin University, Australia

*Correspondence:

Christopher J. Ennis

c.ennis@tees.ac.uk

Specialty section:

This article was submitted to

Wastewater Management,

a section of the journal

Frontiers in Environmental Science

Received: 12 April 2017

Accepted: 24 July 2017

Published: 14 August 2017

Citation:

Ennis CJ, Clarke J, Neate K,

Cerejeira J and Tull L (2017)

Hydrothermal Extraction of Microalgae

Fatty Acid Influences Hydrochar

Phytotoxicity. Front. Environ. Sci. 5:47.

doi: 10.3389/fenvs.2017.00047
C-25 (1.5\%). Thermal analysis (TGA/DSC) of the hydrochar in air showed calorific values of $10.6 \mathrm{MJ} \mathrm{kg}^{-1}$ (delipidated hydrochar) and $3.1 \mathrm{MJ} \mathrm{kg}^{-1}$ (non-delipidated hydrochar) with the latter exhibiting the presence of volatalizable components. Germination trials were conducted to assess the potential phytotoxic effects of these hydrochars. Delipidated hydrochar showed a germination index of $73 \%$ suggesting the presence of some phytotoxicity. Non-delipidated hydrochar showed high germination index results of 102\% (unground) and 126\% (ground). Taken together with the observation of reduced root hair proliferation in these two test conditions, this suggests the operation of a second phytotoxic effect that is removed by delipidation.

\section{Keywords: hydrothermal carbonization, algal biodiesel, biodiesel, biochar, hydrochar}

\section{INTRODUCTION}

As climate change and other serious environmental challenges intensify, there is a growing need for circular-economic approaches to resource recovery and pollution prevention; the integrated biorefinery is a promising concept in this respect. Approximately 11 million tons of waste water are processed each day in UK, coming from a range of commercial, industrial, and public sources (Department for Environment, Food and Rural Affairs , 2012). The treatment of such masses to remove organic, inorganic, and anthropogenic compounds is costly, hence the recycling of such byproducts, for example ammonia, nitrogen, and phosphorus, is being explored as a potential route to add value into the water treatment process. Microalgae grown in wastewater can remove toxic material, produce oxygen, and reduce $\mathrm{pH}$ during photosynthesis, having disinfecting effects. The presence of inorganic nitrogen and phosphorus in the wastewater stimulate microalgae growth, resulting in a dense bloom which can subsequently be used as a biofuels feedstock (Abdel-Raouf et al., 2012). 
The use of microalgae as a feedstock to replace existing fossil fuels is becoming increasingly attractive due to environmental benefits and reduced food-biofuel competition (Hannon et al., 2010). As microalgae fix carbon during growth via photosynthesis the subsequent combustion of the biomass is notionally carbon neutral.

Diatoms are important in aquatic ecosystems and have broad industrial potential (Huysmann et al., 2010; Hildebrand et al., 2012). Phaeodactylum tricornutum is a diatom with an oil content of $20-30 \%$ (Khanal et al., 2010). P. tricornutum is able to acclimate to environmental changes, undergoing modification in its lipid metabolism. Substantial amounts of lipids in the form of triacylglycerides (TAG) can be stored under conditions such as photo oxidative stress and other unfavorable environmental changes (Hu et al., 2008). Polymerized silica within the $P$. tricornutum cell wall supports the accumulation of TAG. Algal triacylglycerides are comprised of mid to long chain fatty acids bound to glycerol and hence alcoholytic transesterification produces methyl esters of fatty acids which are the primary source for biodiesel (Gupta et al., 2011).

Global biodiesel production from renewable sources has increased substantially, and concerns have been raised regarding the displacement of food crops for biofuels (Singh et al., 2011). The application of microalgae for commercial biodiesel production from wastewater is promising (Pittman et al., 2011). However, before the application of microalgae as biofuel becomes economically feasible and widespread, the demand of energy per unit mass of algae harvested must be reduced (Lee and Shah, 2013). The predominant concern is that the energy required to dewater algae is large compared to the overall energy output from the triacylglycerides in the algae (Heilmann et al., 2011).

Hydrothermal carbonization (HTC) of microalgae has received particular attention due to the potential to obtain algal oils without energy intensive removal of water (Heilmann et al., 2011). HTC produces a hydrochar to which algal lipids are adsorbed and the process is thermodynamically favorable as hydrogen and oxygen are removed and carbon values are maintained (Valentas and Heilmann, 2011). Once filtered, hydrochar-bound lipids can be solvent extracted prior to transesterification.

The present study aims to analyse qualitatively and quantitatively the fatty acid methyl ester yield available via hydrochar-mediated extraction of algal lipids from $P$. tricornutum. Furthermore, the co-produced hydrochar is of potential utility as a fuel and/or as a biochar: this study investigates the fuel properties and potential phytotoxicity (an important limiting factor on the application of hydrochar as biochar) of the coproduced hydrochar, particularly with a view to investigating potential moderation of hydrochar phytotoxicity during the delipidation process.

\section{METHODS}

\section{Hydrothermal Carbonization of Microalgae}

HTC was done in a $100 \mathrm{ml}$ Buchi MiniClave heated by a Julabo $\mathrm{HE}-4$ oil bath. Four replicate preparations were done using $4 \mathrm{~g}$ samples of freeze-dried microalgae $P$. tricornutum. These were added to $50 \mathrm{ml}$ of $0.1 \mathrm{M}$ citric acid solution and hydrothermally carbonized at $\sim 210^{\circ} \mathrm{C}$ for $2 \mathrm{~h}$, under an average pressure of 20 bar. The four samples were filtered and washed with deionized water.

\section{Delipidation of HTC Char}

To remove adsorbed lipids, HTC chars were stirred overnight in hexane $(40 \mathrm{ml})$, gravity filtered, and washed with hexane $(40 \mathrm{ml}$ approx.). The filter paper with the delipidated char was stored in the fridge $\left(\sim 4^{\circ} \mathrm{C}\right)$ and the filtrate evaporated by a water bath until only non-evaporable material remained.

\section{Transesterification}

Recovered non-evaporable material $(25 \mathrm{mg}$ ) was added to a headspace vial and mixed with methanolic $\mathrm{NaOH}$ solution $(0.5$ $\mathrm{M}, 1.25 \mathrm{ml}$ ). The process was repeated for triplicate $\mathrm{C} 16, \mathrm{C} 18$, and C20 fatty acid calibration standards. All the samples were heated at $100^{\circ} \mathrm{C}$ for $7 \mathrm{~min}$, allowed to cool, mixed with $50 \% \mathrm{BF}_{3}(2 \mathrm{ml})$, and returned to the heat for $5 \mathrm{~min}$. The samples were cooled to $30-40^{\circ} \mathrm{C}$ and mixed by shaking with hexane $(2 \mathrm{ml})$ and saturated $\mathrm{NaCl}(5 \mathrm{ml})$ and left to separate. The top layer was collected to a headspace vial. Hexane $(2 \mathrm{ml})$ was added a further two times to the samples and each time the top layer was collected into the headspace vial. The samples collected were evaporated to dryness using nitrogen, followed by re-dissolution in hexane $(2 \mathrm{ml})$.

\section{GC-MS Analysis}

Fatty acid methyl ester yields of transesterification were analyzed by GC-MS as follows. Samples $(1 \mu \mathrm{l})$ were injected at $300^{\circ} \mathrm{C}$ into a Perkin Elmer Elite 5 MS capillary column $(30 \mathrm{~m} \times 0.25 \mathrm{~mm}$ $\times 0.25 \mu \mathrm{m})$. The oven temperature was held at $60^{\circ} \mathrm{C}$ for $1 \mathrm{~min}$

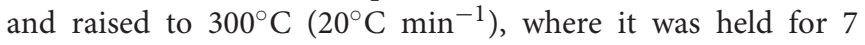
min. The carrier gas was helium $\left(1.0 \mathrm{ml} \mathrm{min}^{-1}\right)$. Quantitative calibration was achieved by running a series of fatty acid methyl esters at known concentration and integrating the peak area in the resulting chromatograms.

\section{Fuel Properties Testing}

Delipidated algal hydrochar was analyzed by thermal gravimetric analysis (TGA) with combined differential scanning calorimetry (DSC). Hydrochar samples were heated in air to $800^{\circ} \mathrm{C}\left(10^{\circ} \mathrm{C}\right.$ $\left.\min ^{-1}\right)$.

\section{Germination Tests}

Three $50 \mathrm{mg}$ samples of delipidated hydrochar were washed sequentially with acetone, ethanol, and deionized water. Six $50 \mathrm{mg}$ samples of non-delipidated hydrochar, three of which were ground using a ceramic pestle and mortar, were washed with deionized water. The filter papers holding the hydrochar samples were transferred to petri dishes and 20 cress seeds added. Three petri dishes containing moist filter paper and 20 cress seeds acted as a control. Each filter paper was saturated with water and, for 7 days, five drops of water was added daily. The number of germinated seeds and the lengths of their shoots and radicles were measured after 7 days and the germination index (GI; Tiquia, 
2010) calculated as:

$$
G I=\frac{R S G \times R R G}{100}
$$

where RSG (relative seed growth) is given by:

$$
R S G=\frac{N_{\text {hydrochar }}}{N_{\text {control }}}
$$

and RRG (relative root growth) is given by:

$$
R R G=\frac{L_{\text {hydrochar }}}{L_{\text {control }}}
$$

where: $\mathrm{N}$, number of seeds germinated; L, mean root length.

\section{Statistics}

Testing for statistically significant difference in the germination trials was done by ANOVA using IBM SPSS version 23 at the 95\% confidence level and are reported here including the $F$-ratio, the significance level, and the effect size. Unless otherwise stated, error limits are reported as $95 \%$ confidence intervals.

\section{RESULTS}

\section{Oil Extraction Efficiency}

Over the three replicate HTC experiments $7.48 \pm 0.08 \%$ of input algal biomass was recovered as non-evaporable material following hexane extraction of the solid hydrochar product. From the perspective of production of algal biofuels it is important to understand the profile of fatty acids within this extract. To assess this, the extracted oil was transesterified and quantitatively analyzed using GC-MS.

\section{Fatty Acid Profile of Lipid Extract}

Quantitative GC-MS analysis was performed on transesterified extracts from the three replicate HTC preparations. Major analyte peaks are seen at retention times of 9.02, 10.01, 10.10, 10.93, $11.06,11.90$, and $13.94 \mathrm{~min}$. Mass spectra at each retention time were characteristic of either saturated or unsaturated fatty acid methyl esters. Representative examples from our data are shown in Figure 1.

In the following, an abbreviation convention of fatty acid identity is adopted in which a fatty acid with 16 carbon atoms and no unsaturation (hexadecanoic acid; palmitic acid) is referred to as 16:0 while a mono-unsaturated acid with 18 carbon atoms (e.g., cis-9-octadecenioc acid; oleic acid) is referred to as $18: 1$ etc.

All mass spectra in the GC-MS chromatogram show the McLafferty ion at $m / z=74$ characteristic of methyl ester $\beta$-cleavage of the molecular ion shown in Figure 2.

Furthermore, spectra display the molecular ion $\left(\mathrm{M}^{+}\right)$ characteristic of the fatty acid methyl ester chain length. On the basis of these molecular ion signals, the spectra in Figure $\mathbf{1}$ have been assigned to the relevant fatty acid. Further characteristic features of the mass spectra of saturated fatty acid methyl esters are the loss of methoxy moiety from the molecular ion ([M$31]^{+}$) and loss of $\mathrm{C}_{3} \mathrm{H}_{7}$ moiety $\left([\mathrm{M}-43]^{+}\right)$through eliminative

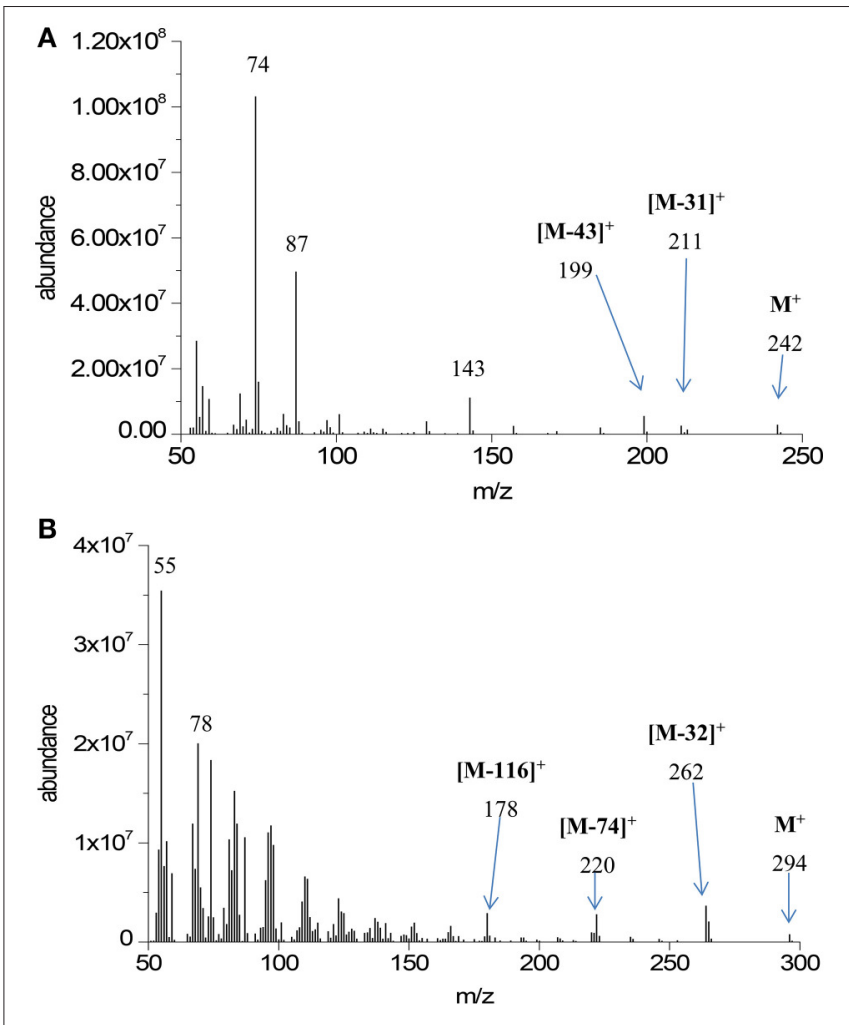

FIGURE 1 | Mass spectra for chromatographic peaks at (A) $9.02 \mathrm{~min}$; (B) $10.93 \mathrm{~min}$.

rearrangement at the hydrocarbon end of the molecule. As the mass spectrometer used here is not capable of detection above $m / z=350$, molecular ions of 22:0 and heavier fatty acid methyl esters are not detectable. The assignment of the fatty acid methyl ester at $\mathrm{RT}=13.94 \mathrm{~min}$ as methyl tetracosanoate (24:0) is made on the basis of the characteristic M-43 ion seen at $m / z=339$. Other notable features of the mass spectra of the saturated fatty acid methyl esters are the peaks due to $\left[\mathrm{MeOCO}\left(\mathrm{CH}_{2}\right)_{n}\right]^{+}$ starting at $m / z=87(n=2)$.

Characteristics of the mass spectra of unsaturated fatty acid methyl esters include the McLafferty ion $(\mathrm{m} / z=74)$ and loss thereof $\left([\mathrm{M}-74]^{+}\right)$, loss of methanol $\left([\mathrm{M}-32]^{+}\right)$, and a homologous series of fragments resulting from loss of neutral $\mathrm{MeOCO}\left(\mathrm{CH}_{2}\right)_{n} \mathrm{CH}_{3}$, with $n=3$ resulting in $[\mathrm{M}-116]^{+}$. An homologous series of peaks representing $\left[\mathrm{C}_{n} \mathrm{H}_{2 n-1}\right]^{+}$is also evident in the mass spectra of unsaturated fatty acid methyl esters, beginning with the base peak at $m / z=55$ $(n=4)$.

From these mass spectra the assignment of retention time to fatty acid methyl ester structure can be made with some certainty; this is outlined in Table 1. Integrated areas of the relevant chromatographic peak have been used to evaluate the relative contribution of each fatty acid to the overall fatty acid profile of the extracted triacylglycerides. This relative composition is also shown in Table 1. The overall yield of the transesterification reaction, based on the mass of lipid extracted from the solid char, was $94 \pm 10 \%$. 

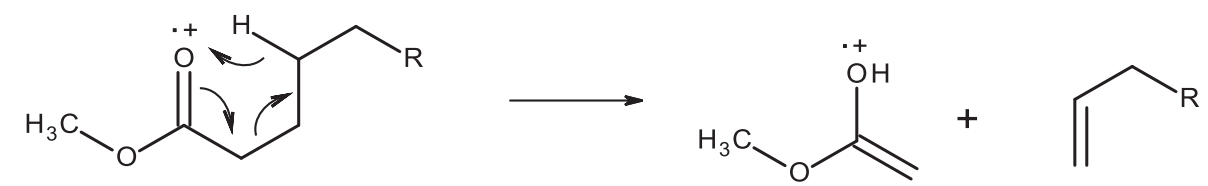

FIGURE 2 | Methyl ester $\beta$-cleavage of the molecular ion.

TABLE 1 | Assignment of GC-MS retention time to fatty acid methyl ester structure and the relative composition of each component of the extracted oil.

\begin{tabular}{lccc}
\hline $\begin{array}{l}\text { Fatty acid } \\
\text { methyl ester }\end{array}$ & $\mathbf{m} / \mathbf{z}$ of $\mathbf{M}^{+}$ & $\begin{array}{c}\text { Retention } \\
\text { time/min }\end{array}$ & $\begin{array}{c}\text { Relative composition } \\
\text { of extracted oil/\% }\end{array}$ \\
\hline $14: 0$ & 242 & 9.02 & $5.3 \pm 2.0$ \\
$16: 0$ & 270 & 10.10 & $37.2 \pm 0.7$ \\
$16: 1$ & 268 & 10.01 & $40.4 \pm 6.6$ \\
$16: 2$ & 266 & $\mathrm{ND}$ & $\mathrm{ND}$ \\
$16: 3$ & 264 & $\mathrm{ND}$ & $\mathrm{ND}$ \\
$18: 0$ & 298 & 11.06 & $1.9 \pm 0.8$ \\
$18: 1$ & 296 & 10.93 & $7.7 \pm 3.0$ \\
$18: 2$ & 294 & $\mathrm{ND}$ & $\mathrm{ND}$ \\
$18: 3$ & 292 & $\mathrm{ND}$ & $\mathrm{ND}$ \\
$20: 0$ & 326 & 11.90 & $0.16 \pm 0.11$ \\
$25: 0$ & 382 & 13.49 & $1.5 \pm 0.3$ \\
\hline
\end{tabular}

ND, not detected.

\section{Thermogravimetric Analysis}

The TGA and DSC data obtained by heating delipidated and non-delipidated algal biochar in air are displayed in Figure 3. During heating of the delipidated algal biochar a strong exotherm is observed between 150 and $680^{\circ} \mathrm{C}$; integrating this exothermic heat flow yields a calorific value of $10,600 \mathrm{~kJ} \mathrm{~kg}^{-1}$. The DSC of the non-delipidated char shows two sudden endotherms between 300 and $420^{\circ} \mathrm{C}$ but is largely exothermic. Integrating the exothermic heat flow yields a calorific value of $3,090 \mathrm{~kJ} \mathrm{~kg}^{-1}$.

\section{Germination Trials}

Germination trial results are displayed in Figure 4. There is no significant effect of hydrochar on the relative seed growth, $F_{(2,6)}=0.50, p=0.629$. Root growth, and consequently germination index, is supressed in the delipidated hydrochar growth condition, being 76 and $73 \%$, respectively. Both these measures are $>100 \%$ in the non-delipidated hydrochar conditions, with GI $=102$ and $126 \%$ for the non-delipidated and non-delipidated, ground hydrochar growth conditions, respectively. That is, roots from the seeds germinated on nondelipidated hydrochar were longer than those from the control seeds after 7 days.

These effects of hydrochar on RRG and on GI are statistically significant, as follows. There is a significant, large effect of hydrochar treatment on relative root growth, $F_{(2,6)}=7.86$, $p=0.021, \omega=0.78$. Post-hoc testing (Turkey HSD) reveals that ground, non-delipidated hydrochar significantly increased RRG relative to delipidated hydrochar $(p=0.017)$. Consequently, there is a significant, large effect of hydrochar treatment on germination index, $F_{(2,6)}=7.22, p=0.025, \omega=0.76$. Posthoc testing (Turkey HSD) reveals that ground, non-delipidated hydrochar significantly increased germination index relative to delipidated hydrochar $(p=0.021)$.

\section{DISCUSSION}

The extraction efficiency of algae lipids is relatively low: a yield of $\sim 7 \%$ of biomass compared to a lipid content of $47 \% \pm$ $6 \%$ (standard error) in the original $P$. tricornutum biomass (data from Swansea University-see Section Acknowledgments). Although the focus of this study was not concerned with extraction efficiency but with the fatty acid profiles of the extracted lipids, it is valuable to note that, for example, Fajardo et al. (2007) improved recovery of lipids from biomass using a two-step extraction. The first step used ethanol to extract $77.4 \%$ of algal lipids, then a mixed solvent second step extracted a further $18.7 \%$ of lipids.

Good quality biodiesel should have a 5:4:1 fatty acid ratio of 16:1, 18:1, and 14:0 (Schenk et al., 2008). The relative composition of the algae oil extracted from the hydrochar resulting from HTC of $P$. tricornutum has a ratio of 8:1.6:1 approximately, with 16:1 being the most abundant followed by 16:0, a saturated fatty acid. A balance in saturated and unsaturated fatty acid maintains high quality biodiesel standards. Saturated fatty acids such as 16:0 are, however, desirable as they have higher oxidative stability, excellent combustion properties, such as cetane number and high calorific value, although they impart poor melting and pouring characteristics to the biodiesel, which can compromise quality (Redel-Macias et al., 2012).

The range of fatty acids which are produced is limited by the species and strain and ultimately by the genetic makeup of an organism. A review of microalgae strains identified that many microalgae strains do not accumulate high 16:1 and 18:1 together; instead, the production of one of these fatty acid moieties is favored at the expense of the other (Nascimento et al., 2013; Talebi et al., 2013). This trend is not only displayed in microalgae strains but also in crops for biofuels (Ma and Hanna, 1999). In the case of $P$. tricornutum accumulation of 18:1 has been disadvantaged. However, culture condition may have some influence over the relative amount of individual fatty acids (Lang et al., 2011). The effect of nutrient stress on the fatty acid composition of $P$. tricornutum has been studied previously with respect to both nitrogen and phosphorus limitation. Reduction of nitrogen concentration increased overall lipid recovery by $6 \%$ approximately, whereas nitrogen limitation 


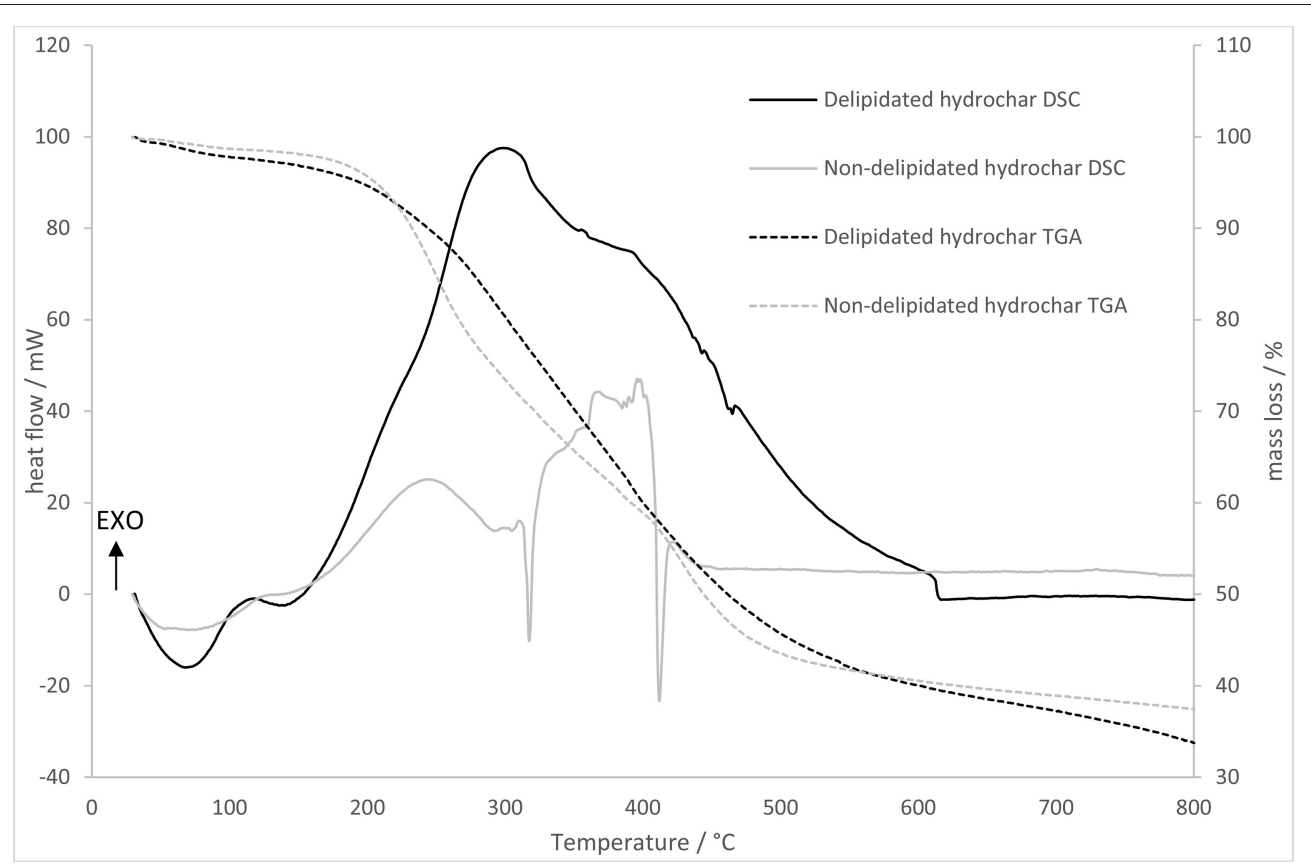

FIGURE 3 | Thermogravimetric analysis (right hand axis) and differential scanning calorimetry (left hand axis) showing mass loss and heat flows for delipidated and non-delipidated hydrochar.

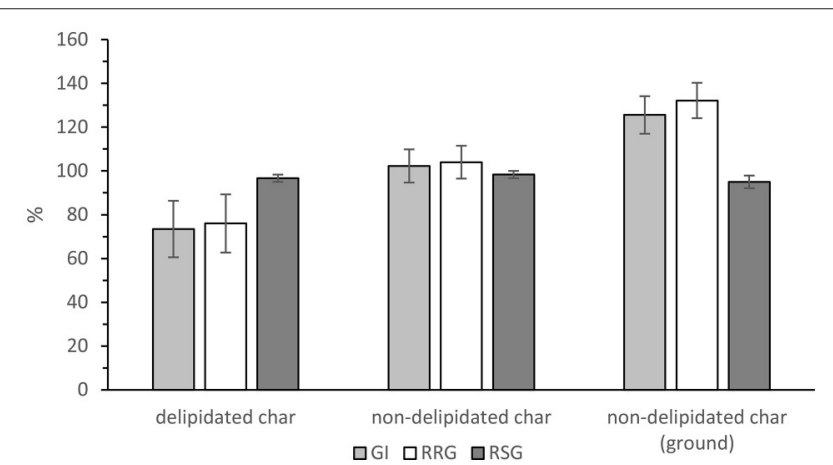

FIGURE 4 | Relative seed growth (dark gray bar), relative root growth (white bar), and germination index (light gray bar) for the three growth conditions. Error bars are \pm standard error of the mean $(n=3)$.

increased 16:0 and 18:1 yield (Sharma et al., 2012). Genetic modification targeting key enzymes in lipid biosynthesis is also a promising target to increase quality and quantity of key fatty acids (Schenk et al., 2008). Although these nutrient limited conditions increase the quantity and quality (from a biodiesel production perspective) of fatty acids in $P$. tricornutum they are unlikely to be met in the context of a wastewater treatment integrated biorefinery. Nonetheless, biodiesel-quality fatty acid compositions are available from this organism under a range of relevant conditions and are accessible via HTC processing. Optimization, in terms of triacylglyceride recovery protocols, as well as genetic modification and/or culture based bioaugmentation are accessible and viable routes for improving the quality and quantity of lipids recovered by HTC.
The extraction of lipids results in the co-production of a delipidated hydrochar. Hydrochar has been proposed as a suitable soil amendment to improve soil physicochemical properties (Titirici, 2013). However, hydrochars have been demonstrated to exhibit phytotoxic effects (Bargmann et al., 2013). We hypothesize that hydrochar delipidation with hexane will moderate phytotoxicity by removal of toxic organic adsorbates.

As seen in Figure 3, delipidated and non-delipidated chars exhibit different thermal mass loss (TGA) and heat flow (DSC) trends, as well as different calorific values. Previous studies have shown hydrochar to have a range of calorific values that are somewhat higher than those observed in this study. For example, food-waste derived hydrochar calorific values range between 17.0 and $33.7 \mathrm{MJ} \mathrm{kg}^{-1}$ (Yin et al., 2017), hydrochar produced by HTC of the macrophyte Ceratophyllum demersum has a calorific value between $24.11 \mathrm{MJ} \mathrm{kg}^{-1}$ (non-catalytic HTC) and $29.0 \mathrm{MJ} \mathrm{kg}^{-1}$ (KOH-catalyzed HTC; Rather et al., 2017). We postulate that the observed low calorific value of delipidated $P$. tricornutum-derived hydrochar $\left(10.6 \mathrm{MJ} \mathrm{kg}^{-1}\right)$ is due to the high silica content of the biomass and consequently the enriched ash content of the hydrochar. Low calorific value, high ash chars have been observed in a comparative study of biomass $\mathrm{HTC}$ at $200^{\circ} \mathrm{C}$ by Smith et al. (2016). For sewage treatment sludge the calorific value and ash content were, respectively, $6.0 \mathrm{MJ} \mathrm{kg}^{-1}$ and $78.7 \%$, whilst the values were 9.1 MJ kg ${ }^{-1}$ and $74.8 \%$ for anaerobic digestion press cake and 24.4 MJ kg-1 and $12.9 \%$ for food waste. The ash content of the $P$. tricornutum-derived hydrochar can be inferred from Figure 3 (as the residual mass at $800^{\circ} \mathrm{C}$ ) as $\sim 35 \%$, broadly in line with the ash content-calorific value relationship observed by Smith 
et al. The extreme low calorific value for the non-delipidated material is an experimental artifact: exothermic heat flow from the combustion of the volatalized organics is not measured by the TGA apparatus.

Non-delipidated char exhibits a mass loss rate that is rapid compared to that for the delipidated char at low temperature $\left(<500^{\circ} \mathrm{C}\right)$ and two sharp endotherms at 320 and $410^{\circ} \mathrm{C}$. The delipidated char, by contrast, shows a large exotherm in the temperature range $200-600^{\circ} \mathrm{C}$ corresponding to the combustion of cellulosic material $\left(<400^{\circ} \mathrm{C}\right)$ and refractory $\mathrm{C}\left(500-550^{\circ} \mathrm{C}\right.$; Lehmann and Joseph, 2009). Since combustion of organic matter in an oxidizing atmosphere is an exothermic process, whist the volatalization of organic material is endothermic, we interpret these data as follows. Mass loss as a function of temperature occurs as the solid hydrochar undergoes combustion in both cases. In the case of the non-delipidated material this exotherm is off-set to a large extent by the coincident endotherm due to volatalization of the surface adsorbed oils (Wendlandt, 1986). No such volatilization occurs for the delipidated material. This is a reasonable expectation as the lipids liberated from the microalgae biomass during HTC are subsequently adsorbed onto the surfaces of the hydrochar as it forms. It is these adsorbed lipids that are the target of the delipidation (and subsequent transesterification). In addition to the removal of lipids, we suggest that delipidation (solvent extraction with a non-polar solvent) removes potentially harmful volatile organic substances known to be present in poorly-carbonized biochars (Ghidotti et al., 2017) and in many hydrochars (Reza et al., 2014), based on the indication of less rapid low-temperature mass loss and the absence of low temperature endotherms in the TGA/DSC data for the delipidated material.

Furthermore, volatile compounds such as these may be associated with phytotoxic effects (Bargmann et al., 2013; Melo et al., 2017). There is no statistically significant difference in the relative germination number between the three conditions tested in the growth trials-all three hydrochar conditions do not affect the number of cress seeds germinating. However, there is a significant difference between the non-delipidated and delipidated chars in terms of the impact of hydrochar on root length: for both the non-delipidated conditions (ground and un-ground) in the germination trial, root length increased relative to that in the controls (Figure 4). This is also reflected in the germination indexes which, for both the non-delipidated hydrochar conditions, are in excess of $100 \%$. In contrast, the delipidated hydrochar exhibits a suppressive effect on root length, relative to the control. Furthermore, root hair growth was sparse in the two non-delipidated conditions as shown in the photographs of Figure 5, whilst root hairs were clearly visible in both the control (not shown) and in the delipidated condition: their development is evidently retarded for those seeds treated with non-delipidated hydrochar. In the case of the un-ground non-delipidated material, root hair growth is retarded, with both the number-density and length of root hairs being negatively impacted. For the ground, non-delipidated hydrochar germination trial, the germinated seedlings at day seven are seen to be almost devoid of root hairs.

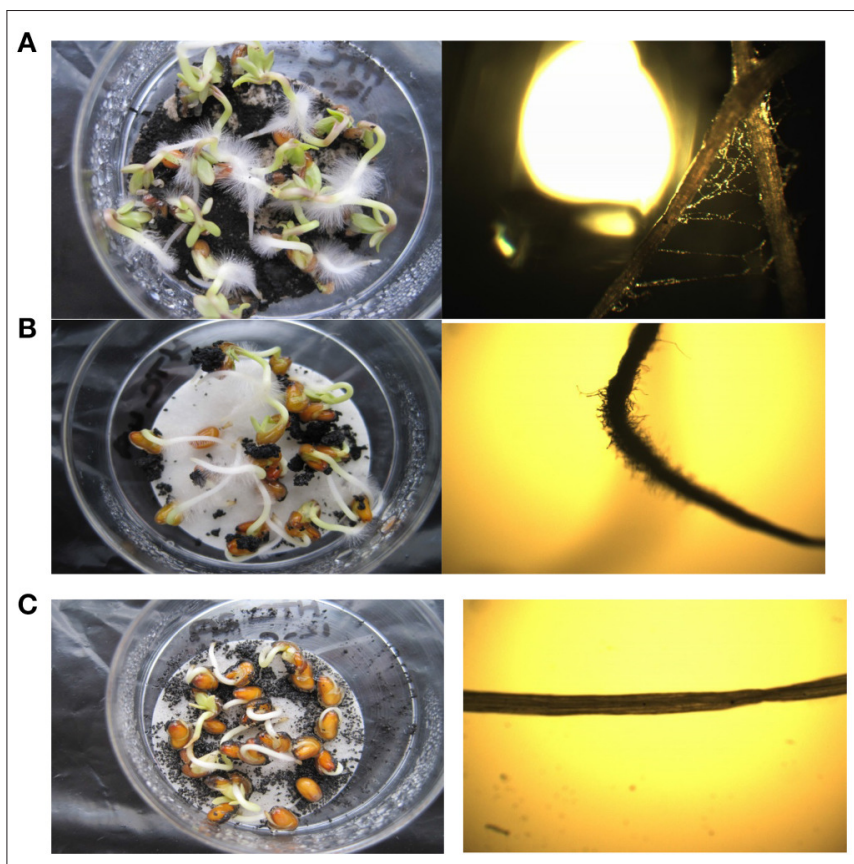

FIGURE 5 | Representative photographs (left hand column) and photomicrographs (right hand column) of root hair growth pattern after 7 days in: (A) delipidated hydrochar growth condition; (B) non-delipidated hydrochar growth condition; (C) ground, non-delipidated growth condition.

Inhibition of root hair development can be a result of chemical disruption of the cytoskeleton development (Park and Nebenfuhr, 2011). Although root hairs are not crucial for plant growth, they provide increased surface area to assist in water and nutrient uptake. It is tentatively proposed that the increased root length exhibited by the non-delipidated hydrochars is a response to chemical root hair inhibition resulting from the presence of phytotoxic agents on the surface of the non-delipidated hydrochar (Reza et al., 2014). The growing seedlings respond to this inhibition by lengthening the root, increasing surface area and promoting uptake of water and nutrients in the absence of root hairs. This effect is intensified by increased hydrochar surface area in the ground, non-delipidated condition and hence increased availability of surface-adsorbed phytotoxic agents. Therefore, we observe the apparent operation of a phytotoxic effect resulting in the retardation of root hair growth and, furthermore, that this effect is removed by the process of delipidation, viz., extraction with hexane.

It is likely, therefore, that there are at least two competing effects that impact on the health of the germinating plant. In the first place there is the presumably chemical effect described above that suppresses root hair growth and that is mediated by chemical species that are removed by the delipidation process. Secondly, there is an effect-chemical, physical, or both-that operates to suppress root length in the presence of delipidated hydrochar. These effects presumably operate in parallel in the non-delipidated hydrochar germination condition. The first of these phytotoxic mechanisms is removed by the delipidation protocol described in this work. Hence, the HTC 
of $P$. tricornutum biomass followed by delipidation of the resulting hydrochar is a route to fatty acids of relevance to biodiesel production and coproduces a hydrochar, the potential phytotoxicity of which is at least in part mitigated in the process.

\section{CONCLUSION}

Following the work of Heilmann et al. (2011), we have demonstrated successful extraction of biodiesel precursors by HTC of P. tricornutum, an organism of potential relevance to the waste-water treatment industry as a method of phosphate removal. The concomitant production of lipids has the potential to add significant value to this route, supporting its development as an enabling technology for an integrated biorefinery. The co-produced hydrochar is also a potential source of added value in this concept and we have shown that the process of obtaining the lipids relevant to biodiesel production also mitigates the phytotoxicity (and potentially enhances the calorific value) of the hydrochar, opening the possibility of its use in soil amendment and climate mitigation. That is, removal of the

\section{REFERENCES}

Abdel-Raouf, N., Al-Homaidan, A. A., and Ibraheem, M. B. I. (2012). Microalgae and wastewater treatment. Saudi J. Biol. Sci. 19, 257-275. doi: 10.1016/j.sjbs.2012.04.005

Bargmann, I., Rillig, C. M., Buss, W., Kruse, A., and Kuecke, M. (2013). Hydrochar and biochar effects on germination of spring barley. J. Agron. Crop Sci. 199, 360-373. doi: 10.1111/jac.12024

Department of Environment, Food and Rural Affairs (2012). Implementation of the European Union Urban Waste Water Treatment Directive - 91/271/EEC. Available online at: https://www.gov.uk/government/uploads/system/uploads/ attachment_data/file/69592/pb13811-waste-water-2012.pdf

Fajardo, R. A., Cardan, E. L., Medina, R. A., Ferandez, A. G. F., Moreno, G. A. P., and Grima, M. E. (2007). Lipid extraction from microalga Phaeodactylum tricornutum. Eur. J. Lipid Sci. 109, 120-126. doi: 10.1002/ejlt.200600216

Ghidotti, M., Fabbri, D., and Horning, A. (2017). Profiles of volatile organic compounds in biochar: insights into process conditions and quality assessment. Sustain. Chem. Eng. 5, 510-517. doi: 10.1021/acssuschemeng. $6 \mathrm{~b} 01869$

Gupta, N. G., Tiwari, K. S., Lawrence, K., and Lawrence, S. R. (2011). Effects of silicon on growth and biodiesel production in fresh water diatoms. Plant Arch. $11: 2$

Hannon, M., Gimpel, J., Tran, M., Rasala, B., and Mayfield, S. (2010). Biofuels from algae: challenges and potential. Biofuels 1, 763-784. doi: 10.4155/bfs.10.44

Heilmann, M. S., Jader, R. L., Harned, A. L., Sadowsky, J. M., Schendel, J. F., Lefebvre, A. P., et al. (2011). Hydrothermal carbonization of microalgae II. Fatty acid, char and algal nutrient products. Appl. Energy 88, 3286-3290. doi: 10.1016/j.apenergy.2010.12.041

Hildebrand, M., Davis, A. K., Smith, S. R., Traller, J. C., and Abbriano, R. (2012). The place of diatoms in the biofuels industry. Biofuels. 3, 221-240. doi: 10.4155/bfs.11.157

Hu, Q., Sommerfield, M., Jarvis, E., Ghirardi, M., Posewitz, M., and Seibert, M. (2008). Microalgal triacylglycerol's as feedstock's for biofuel production: perspectives and advances. Plant J. 54, 621-639. doi: 10.1111/j.1365-313X.2008.03492.x

Huysmann, J. M., Martens, C., Vandepoele, K., Gillard, J., Rayko, E., Eijde, M., et al. (2010). Genome-wide analysis of the diatom cell cycle unveils a novel type of cyclins involved in environmental signaling. Genome Biol. 11:R17. doi: 10.1186/gb-2010-11-2-r17

Khanal, K. S., Surampalli, Y. R., Zhang, C. T., Lamsal, B. P., Tyagi, R. D., and Kao, C. M. (2010). Bioenergy and Biofuel from Biowastes and Biomass. Reston, VA: ASCE. biodiesel precursors from the hydrochar has the co-benefit of making the hydrochar more suitable for agricultural application as biochar.

\section{AUTHOR CONTRIBUTIONS}

CE, Lead author and project leader. LT, JCe, and KN were junior researchers working in CE laboratory specifically employed for this project by Teesside University funding. JCl was a senior researcher in $\mathrm{CE}$ lab and managed much of the day-to-day activities of the researchers.

\section{ACKNOWLEDGMENTS}

The authors would like to thank the University of Teesside University Research Fund for funding this work and Teesside University's Student as a Researcher scheme for funding their research work of LT, JCe, and KN. CE would like to thank Dr. Robin Shields, Dr. Alla Silkina, and Mr. Craig Pooley of Swansea University for provision of the P. tricornutum used in this work.

Lang, I., Hodac, L., Friedl, T., and Feussner, I. (2011). Fatty acid profiles and their distribution patterns in microalgae: a comprehensive analysis of more than 2000 strains from the SAG culture collection. BMC Plant Biol. 11:124. doi: 10.1186/1471-2229-11-124

Lee, S., and Shah, T. Y. (2013). Biofuels and Bioenergy: Processes and Technologies. London: Taylor Francis.

Lehmann, J., and Joseph, S. Eds. (2009). Biochar for Environmental Management: Science and Technology, 1st Edn. London: Earthscan.

Ma, F., and Hanna, A. M. (1999). Biodiesel production a review. Biosource Technol. 70, 1-15. doi: 10.1016/S0960-8524(99)00025-5

Melo, T. M., Bottlinger, M., Schulz, E., Leandro, W. M., de Aguiar Filho, A. M., Ok, Y. S., et al. (2017). Effect of biosolid hydrochar on toxicity to earthworms and brine shrimp. Environ. Geochem. Health. doi: 10.1007/s10653-017-9995-5. [Epub ahead of print].

Nascimento, A. I., Marqyes, I. S. S., Cabanelas, D., Pereira, T. I., Druzian, J. I., de Souza, C. O., et al. (2013). Screening microalgae strains for biodiesel production: lipid productivity and estimation of fuel quality based on fatty acid profiles as selective criteria. Bioenergy Resour. 6, 1-13. doi: 10.1007/S12155-012-9222-2

Park, E., and Nebenfuhr, A. (2011). "Cytoskeleton and root hair growth," in The Plant Cytoskeleton, ed B. Liu (New York, NY: Springer), 259-275.

Pittman, J. K., Dean, A. P., and Osundeko, O. (2011). The potential of sustainable algal biofuel production using wastewater resources. Bioresour. Technol. 102, 17-25. doi: 10.1016/j.biortech.2010.06.035

Rather, M. A., Khan, N. S., and Gupta, R. (2017). Catalytic hydrothermal carbonization of invasive macrophyte Hornwort (Ceratophyllum demersum) for production of hydrochar: a potential biofuel. Int. J. Environ. Sci. Technol. 14, 1243-1252. doi: 10.1007/s13762-016-1227-5

Redel-Macias, D. M., Pinzi, S., Ruz, F. M., Cunero-Atienza, J. A., and Dorado, P. M. (2012). Biodiesel from saturated and monounsaturated fatty acid methyl esters and their influence over noise and air pollution. Fuel 97, 751-756. doi: 10.1016/j.fuel.2012.01.070

Reza, M. T., Andert, J., Wirth, B., and Mumme, J. (2014). Hydrothermal carbonization of biomass for energy crop production. Appl. Bioenergy 1, 11-29. doi: 10.2478/apbi-2014-0001

Schenk, M. P., Thomas-Hall, R. S., Stephens, E., Marx, C. U., Mussgnug, H. J., and Posten, C. (2008). Second generation biofuels: high efficiency microalgae for biodiesel production. Bioenergy Resour. 1, 20-43. doi: 10.1007/s12155-008-9008-8

Sharma, K. K., Schuhmann, H., and Schenk, M. P. (2012). High lipid induction in microalgae for biodiesel production. Energies 5, 1532-1553. doi: $10.3390 /$ en5051532 
Singh, A., Nigam, S. P., and Murphy, D. J. (2011). Renewable fuels from algae: an answer to debatable land based fuels. Bioresour. Technol. 102, 10-16. doi: 10.1016/j.biortech.2010.06.032

Smith, A. M., Singh, S., and Ross, A. B. (2016). Fate of inorganic material during hydrothermal carbonization of biomass: influence of feedstock on combustion behavior of hydrochar. Fuel 169, 135-145. doi: 10.1016/j.fuel.2015.12.006

Talebi, F. A., Mohtashami, K. S., Tabatabbael, M., Tohidfar, M., Bagheri, A., and Zeinalabedini, M. (2013). Fatty acids profiling: as selective criterion for screening microalgae strains for biodiesel production. Algal Res. 2, 258-267. doi: 10.1016/j.algal.2013.04.003

Tiquia, S. M. (2010). Reduction of compost phytotoxicity during the process of decomposition. Chemosphere 79, 506-512. doi: 10.1016/j.chemosphere.2010.02.040

Titirici, M. M. (2013). Sustainble Carbon Material from the Hydrothermal Carbonisation Process. Chichester, UK: John Wiley \& Sons.

Valentas, J. K., and Heilmann, M. S. (2011). "Hydrothermal carbonisation: an innovative new process for the extraction of algal oil," in AIChE Annual Meeting. Conference Proceedings. Available online at: https://www.researchgate.
net/publication/267309919_Hydrothermal_Carbonization_An_Innovative_ New_Process_for_the_Extraction_of_Algal_Oil

Wendlandt, W. W. (1986). Thermal Analysis, 3rd Edn. New York, NY: Wiley.

Yin, K., Li, L., Giannis, A., Weerachanchai, P., Ng, B. J. H., and Wang, J.-Y. (2017). High-quality fuel from food waste-investigation of a stepwise process from the perspective of technology development. Environ. Technol. 38, 1735-1741. doi: 10.1080/09593330.2017.1297851

Conflict of Interest Statement: The authors declare that the research was conducted in the absence of any commercial or financial relationships that could be construed as a potential conflict of interest.

Copyright (C) 2017 Ennis, Clarke, Neate, Cerejeira and Tull. This is an open-access article distributed under the terms of the Creative Commons Attribution License (CC $B Y)$. The use, distribution or reproduction in other forums is permitted, provided the original author(s) or licensor are credited and that the original publication in this journal is cited, in accordance with accepted academic practice. No use, distribution or reproduction is permitted which does not comply with these terms. 